\title{
ARTigOS
}

Pedro Pereira Borges ${ }^{1}$

Lucas Augusto da Silva de Souza ${ }^{2}$

\section{CAPACIDADE À LUZ DO ESTATUTO DA PESSOA COM DEFICIÊNCIA}

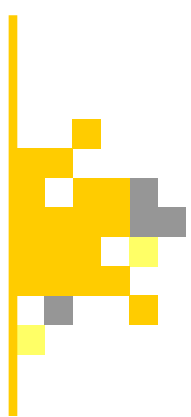

\section{RESUMO:}

A temática do presente estudo foi a personalidade e a capacidade das pessoas com deficiência. O objetivo geral deste artigo foi analisar as mudanças trazidas pela Lei no 13.146/2015 para as pessoas com deficiência no que se refere à capacidade das pessoas naturais. Os objetivos específicos são verificar os conceitos de capacidade na história, identificar os mecanismos que motivaram a criação da lei, verificar as alterações em relação ao Código Civil e abordar as consequências das mudanças no âmbito prático. O tipo de pesquisa foi bibliográfico e procurou apresentar como resultado que toda mudança em ensino e em infraestrutura, seja nos locais públicos, privados ou em meios de transporte ainda precisam ser assumidos pela sociedade em geral se o objetivo for incluir as pessoas com deficiência e dar-lhes a possibilidade de se tornarem pessoas independentes.

Palavras-chaves: Pessoa com deficiência; Capacidade; Estatuto.

\section{ABSTRACT:}

The theme of the present study was the personality and capacity of people with disabilities. The general objective of this article was to analyze the changes introduced by Law 13,146 / 2015 for people with disabilities with regard to the capacity of natural persons. The specific objectives are to verify the concepts of capacity in history, to identify the mechanisms that motivated the creation of the law, to verify the changes in relation to the Civil Code and to address the consequences of the changes in the practical scope. The type of research was bibliographical and sought to present as a result that any change in teaching and infrastructure, whether in public, private or in transportation, still needs to be assumed by society in general if the goal is to include people with disabilities and give the possibility of becoming independent persons.

KeY WORDS: People with disabilities; Capacity; Statute.

\section{INTRODUÇÃO}

O estudo aqui apresentado trata da temática da personalidade e da capacidade das pessoas com deficiência. Trata-se de um assunto que diz respeito ao cotidiano de famílias, comunidades e instituições voltadas para o cuidado e o atendimento a essas pessoas nos seus âmbitos de atua- ção. No que diz respeito às pessoas com deficiência, é importante começar qualquer estudo a partir do aparato jurídico que regula o oferecimento de serviços e o atendimento às suas necessidades.

O objetivo geral deste estudo foi analisar mudanças trazidas pela Lei $n$ o $13.146 / 2015$ para as pessoas com deficiência no que se refere à capacidade das pessoas naturais. Os objetivos específicos são verificar os conceitos de capacidade na histó-

\footnotetext{
${ }^{1}$ Doutor em Ciências Sociais pela PUC-SP, Professor do Programa de Mestrado e Doutorado em Desenvolvimento local da Universidade Católica Dom Bosco. (iD https://orcid.org/0000-0001-9183-5051

${ }^{2}$ Acadêmico do 2 o Semestre do curso de Direito e integrante do Programa Institucional de Bolsas de Iniciação.
} 
ria, identificar os mecanismos que motivaram a criação da lei, verificar as alterações em relação ao Código Civil e abordar as consequências das mudanças no âmbito prático.

O tipo de pesquisa usado para a elaboração para este estudo é bibliográfico, sendo que foram pesquisadas leis e também doutrinas, decisões de tribunais, além de súmulas vinculantes, de 2014 ao ano de 2016. Os autores mais relevantes utilizados para a análise relativa ao Código Civil são Maria Helena Diniz e Flavio Tartuce. Quanto à análise da Constituição sobre o tema das pessoas com deficiência, os autores são Ingo Sarlet, Luiz Guilherme Marinoni e Daniel Mitidiero. Também serão pesquisados textos de âmbito internacional, em especial documentos da Organização das Nações Unidas (ONU) sobre a temática em questão.

Este estudo está estruturado em tópicos, sendo que o primeiro faz um levantamento de artigos publicados sobre o tema nos anos de 2015 e 2016. O segundo tópico tem como tema o conceito de personalidade de direito ao longo da história. O terceiro trata de levantar os mecanismos que motivaram a criação da Lei $n$ ㅇ 13.146/2015. O último tópico tem como foco abordar o quanto essas mudanças impactaram na prática diária da vida das pessoas com deficiência.

\section{ESTADO DA ARTE}

Uma pesquisa realizada na base de dados da Capes fez emergir, entre 2015 e 2016, nove artigos sobre a pessoa com deficiência. $O$ ano de 2015 teve os artigos, Estatuto da Pessoa com Deficiência Altera Regime Civil das Incapacidades, escrito por Maurício Requião (2015), com enfoque às mudanças provocadas no regime das incapacidades do Código Civil brasileiro, em relação ao deficiente que possui transtorno mental. No que diz respeito à valorização do potencial da pessoa com deficiência e também às mudanças na legislação foi encontrado O Estatuto da Pessoa com Deficiência-EPCD (Lei no 13.146, De 06.07.2015), publicado por Luiz Alberto David Araujo e Waldir Macieira da Costa Filho (2015).

Além destes artigos, também foram encontrados, ainda em 2015, os seguintes artigos: As Práticas de Recursos Humanos para a Gestão da Diversidade: a inclusão de deficientes intelectuais em uma federação pública do Brasil, pelas autoras, Nicole Maccali, Paula Suemi Souza Kuabara, Adriana Roseli Wunsch Takahashi, Karina de Déa Roglio e Samantha de Toledo Martins Boeh, é um trabaIho que analisa a interface entre a gestão da diversidade na inclusão de deficientes intelectuais no contexto organizacional e as práticas de recursos humanos geradas a partir dessa nova realidade.

Em relação ao ano de 2016, foram encontrados seis artigos, entre os quais $A$ Inclusão Veio para Ficar: direito antidiscriminatório pós ADI 5357 e a educação inclusiva como direito da pessoa com deficiência, de Bruno Galindo (2016), trata sobre o direito antidiscriminatório, expondo sua definição conceitual e sua importância no contexto da defesa dos direitos da pessoa com deficiência. Há também a análise aos processos de identificação de pessoas com deficiência visual através da audiodescrição, apresentando a emergência da acessibilidade cultural para pessoas com deficiência e o conceito de audiodescrição, de modo a analisar suas possibilidades como uma marca de identificação das pessoas com deficiência visual trazidos pelo artigo Audiodescrição e Processos de Identificação Através da Cultura, de Felipe Leão Miaes (2016).

Outros artigos encontrados no ano de 2016 foram: Inclusão da Pessoa com Deficiência: a grande barreira são as atitudes, por Avanci Duda Xavier (2016), publicado no II Congresso Internacional de Educação Inclusiva, tem como enfoque compreender como tem sido discutida a inclusão da pessoa com deficiência nos textos produzidos pela academia, em uma perspectiva de inclusão, os direitos humanos, bem como as leis positivadas, podem colaborar na quebra das diversas barreiras que têm sido impostas às pessoas com deficiência. As relações jurídicas impactantes na vida da pessoa que adquiriu alguma deficiência ao longo da vida é tratado no artigo $O$ impacto Jurídico e Social na Vida da Pessoa com Deficiência Adquirida, de Va- 
nessa Pereira Dlugosz (2016).

Além destes, também foram encontrados, no ano de 2016, artigos como O Estatuto da Pessoa com Deficiência e as Alterações Jurídicas Relevantes no Âmbito da Capacidade Civil de Silvia Portes Rocha Martins (2016), que aborda as principais alterações determinadas no instituto jurídico da capacidade civil pelo Estatuto da Pessoa com Deficiência.

Estes artigos foram essenciais para esta pesquisa porque ajudaram a perceber a importância de manter a discussão sobre o tema, que é sempre atual.

\section{CAPACIDADE E PERSONALIDADE}

O conceito de capacidade sofreu mudanças ao longo da história, assim como seu alcance às pessoas. Para que a pessoa possa ser considerada sujeito de direitos e obrigações é necessário que ela tenha personalidade. No direito romano não se tinha um conceito bem definido de personalidade, para os romanos o inicio da personalidade jurídica era composto de vários fatores, segundo Rolim (2003), era necessário o nascimento com vida, forma humana e a presença de viabilidade fetal. Preenchendo esses requisitos seria pessoa natural e seria capaz de direitos e obrigações.

\subsection{HISTORICIDADE DA CAPACIDADE}

Segundo Rolim (2003), no Direito Romano, que vigorou desde as origens de Roma até meados do século IV a.C., era chamada de capacidade jurídica ou de direito, aptidão jurídica ou legal de uma pessoa para ser titular de direitos e obrigações, que é inerente ao ser humano desde o seu nascimento até o fim de sua vida, a pessoa que podia praticar diretamente os atos da vida civil sem necessitar da autorização ou sem a necessidade de ser assistido por outra pessoa, possuía a capacidade de fato. Assim como era no direito romano, o Código Civil de 2002, também trata de absoluta- mente capaz as pessoas que possuem as duas capacidades.

Nem todas as pessoas no direito romano chegavam a ser absolutamente capazes, havia causas que limitava a pessoa apenas à capacidade jurídica necessitando de interferência de outra pessoa para atos da vida civil, causas restritivas de capacidade como: a idade, sexo, enfermidades físicas e mentais, a prodigalidade, a infâmia e a religião. Percebe-se que o direito romano era mais restritivo do que o atual dispositivo brasileiro em relação à capacidade das pessoas.

Havia também requisitos quanto ao status no direito romano para as pessoas serem considerados absolutamente capazes. Para Rolim (2003, p.142) "a pessoa deveria ser titular, concomitantemente, de três espécies de status: o status civitatis, o status libertatis e o status familiae". O status civitatis era a cidadania, ou seja, o indivíduo que estava ligado ao Estado romano, só poderia ter esse status se também tivesse o status libertatis, que era ser livre, pois caso o cidadão viesse a perder sua liberdade, perderia também todos seus direitos e, consequentemente, não teria capacidade para exercer qualquer ato da vida civil, tornando-se absolutamente incapaz. Por fim, o status familiae era a condição da pessoa dentro da própria família, podendo ser submetida a qualquer membro família ou não ser submetida a ninguém, sendo assim, livre para a prática de qualquer ato da vida civil (ROLIM, 2003, p. 154).

Vale ressaltar que os romanos tinham como fonte do seu direito os costumes. Eles tiveram por muito tempo observado um determinado comportamento social (ROLIM, 2003). Isso teve importante influência no trato da capacidade das pessoas, pois os costumes demoram anos para serem moldados e aceitos e mais muitos anos para mudar costumes já aceitos. Em relação ao direito natural, que se adapta ao passo que a sociedade evolui, ou seja, em cada momento da história ele pode assumir uma forma, se origina da própria natureza social do homem, de sua experiência e razão (NADER, 2014).

Pode-se dizer que a capacidade jurídica da 
pessoa evoluiu com a história, pois o ser humano passou por experiências e foi mudando seus costumes com o passar do tempo, ampliando o conceito de capacidade jurídica e limitando menos quem pudesse adquirir totalmente a capacidade, podendo, então, adquirir a capacidade absoluta. O próximo tópico tratará da temática da dignidade da pessoa. Não se pode falar de capacidade da pessoa sem antes entender o que é pessoa e o que é dignidade, como será apresentado no tópico seguinte.

\subsection{DIGNIDADE DA PESSOA}

A dignidade, como espécie de princípio fundamental, serve de base para todos os demais princípios e normas constitucionais, inclusive as normas infraconstitucionais. É de tamanha importância a dignidade da pessoa humana que ela aparece como fundamentado para a constituição do Estado Democrático de Direito na Constituição Federal de 1988 que tem fundamentos na Carta das Nações Unidas, Art. 1으, III "A República Federativa do Brasil, formada pela união indissolúvel dos Estados e Municípios e do Distrito Federal, constitui-se em Estado Democrático de Direito e tem como fundamentos: [...] III - a dignidade da pessoa". Além disso, está expressamente garantida no Art. 5, por exemplo, nos incisos, III, não submissão a tortura, IV inviolabilidade da liberdade de consciência e de crença, VII, não privação dos direitos por motivo de crença ou convicção, esses são só alguns dos muitos direitos garantidos no Art. 5ㅇ da Constituição Federal de 1988 que visa preservar e garantir a dignidade da pessoa Para Sarlet, Marinoni e Mitidiero (2015) a dignidade implica para que a pessoa não seja reduzida a uma condição de objeto, seja por meio de ações de outras pessoas ou ações do próprio Estado, constituindo um fundamento dos direitos fundamentais, contra os atos que violem a dignidade da pessoa ou à ameaças e riscos.

A Declaração dos Direitos do Homem e do Cidadão, promulgada pela Organização das Nações Unidas (ONU), em 1948, traz em seu Art. 10 que "todos os homens nascem livres e iguais em digni- dade e direitos". Com isto de entende que todos são titulares de direitos fundamentais. Porém nem sempre a dignidade da pessoa humana foi respeitada no decorrer da história, passando por diversas fases sendo ligada sempre ao conceito de pessoa.

O conceito de dignidade humana vem sendo aperfeiçoado desde tempos antigos, segundo Cleber Francisco Alves (2001) em seu artigo com enfoque na doutrina social da igreja, na Bíblia o ser humano tem valor único, não podendo ser transformado o homem em objeto ou mero instrumento e segundo a Bíblia o homem foi criado à "imagem e semelhança de Deus" (Gn 1), sendo assim inviolável sua dignidade.

No que diz respeito ao sentido filosófico e político, na antiguidade segundo $\mathrm{RECH}$ e ROANI (2013, apud KUMAGAI, 2010), era possível dizer que um sujeito era mais digno do que outro apenas por seu status social. A posição que o individuo na sociedade ocupava estava diretamente ligada à sua personalidade, pois quanto maior fosse a posição ocupada na sociedade, maior seria a sua dignidade, levando, ainda, em consideração o quanto era reconhecido dentro de dada sociedade. É no Código de Hamurabi que podem ser encontrados os primeiros mecanismos de defesa da dignidade como direito do ser humano.

A dignidade está ligada à pessoa humana. Sendo assim surge a necessidade de se perguntar o que é ser pessoa. Segundo Rolim (2003), a palavra persona surgiu das máscaras utilizadas pelos atores nas peças teatrais para dar eco à voz e propagar o som de maneira clara para a plateia. Este sentido foi transformado e passou a exprimir a situação de cada indivíduo no contexto jurídico. O termo persona, com o decorrer do tempo, passou a designar o sujeito de direito nas relações jurídicas. Segundo a filosofia kantiana, pessoa não pode ser um objeto, tem valor absoluto e não está passível de coisificação devendo a pessoa ser vista como um fim em si mesmo (COMPARATO, 2003).

Comparato (2003), com base em Kant, na obra Fundamentação da Metafísica dos Costumes, afirma que uma das três fases na elaboração do conceito de pessoa pontuava que cada ser huma- 
no é insubstituível e não pode ser trocado por qualquer coisa. Baseado também no Boécio, filósofo da Idade Média, Comparato (2003) define pessoa como um ser composto de substância corporal e espiritual, motivando assim o principio da igualdade essencial de todo ser humano.

Nos dias de hoje é pessoa o indivíduo físico ou jurídico que possui direitos, direitos que são adquiridos quando o individuo nasce com vida. É então que adquire personalidade, que é conceito básico da ordem jurídica e atinge todas as pessoas (DINIZ, 2012). Basta então que o indivíduo nasça com vida, não importando se venha a falecer minutos após seu nascimento, para que adquira personalidade (TARTUCE, 2011).

Ao adquirir a personalidade o indivíduo passa a ter também a capacidade de direito ou de gozo, para ser sujeito de direitos e deveres, na qual todas as pessoas possuem independente de sua situação, sendo o único requisito ter personalidade, além da capacidade de direito ou de gozo, há também a capacidade de fato que é aquela para exercer direitos, essa capacidade pode também ser chamada de capacidade de exercício (TARTUCE, 2011). A última é adquirida quando o indivíduo se torna totalmente capaz para exercer atos da vida civil, ou seja, quando atinge a maior idade. As pessoas com deficiências não atingiam essa capacidade e ficavam sujeitas apenas à capacidade de direito, não se obtendo a capacidade civil-plena, que nada mais é do que a combinação das capacidades de direito mais a capacidade de fato (TARTUCE, 2011).

Pode-se perceber, então, que a capacidade sofreu mudanças no decorrer da história, chegando ao que a lei propõe atualmente, ou seja, de não mais se excluir a pessoas que têm deficiência, permitindo que elas mesmas exerçam seu direito se tornando absolutamente capaz no ordenamento jurídico. Este é um avanço conquistado principalmente pela Convenção Internacional sobre os Direitos da Pessoa com Deficiência, assinada pelo Brasil, que possibilitou fazer as alterações em nossa lei civil, revogando o artigo que tratava o deficiente como pessoa absolutamente incapaz, man- tendo apenas os menores de 16 anos como absolutamente incapaz.

Segundo o Art. 3으, Código Civil de 2002, "São absolutamente incapazes de exercer pessoalmente os atos da vida civil os menores de 16 (dezesseis) anos", ficando sujeito a pessoa com deficiência à curatela apenas em casos extremos e a certos assuntos que serão limitados pelo juiz de ofício. Todas essas mudanças foram motivadas pela inclusão da pessoa com deficiência no meio social e sendo produto de um processo histórico de direitos humanos.

\section{MOTIVAÇÃO PARA A CRIAÇÃO DA} LEI

O estatuto da pessoa com deficiência é resultado de um processo histórico. Em 1989 houve a aprovação de Lei no 7.853. Esta lei dispõe sobre apoio às pessoas com deficiência e sua integração social. Em 1991 a Lei no 8.213 trouxe a garantia de uma porcentagem do total de empregos em empresas para pessoas com deficiência. Este é mais um dispositivo que visa garantir a inclusão da pessoa com deficiência no meio social, promovendo maior acesso ao mercado de trabalho, Art. 93:

\footnotetext{
A empresa com 100 (cem) ou mais empregados está obrigada a preencher de $2 \%$ (dois por cento) a $5 \%$ (cinco por cento) dos seus cargos com beneficiários reabilitados ou pessoas portadoras de deficiência, habilitadas, na seguinte proporção:

I até200 empregados, 2\%;

II de 201 a 500, 3\%;

III - de 501 a 1.000, 4\%;

IV - de 1.001 em diante, $5 \%$.
}

Em 2009 foi ratificada pelo Brasil a Convenção Internacional sobre os Direitos das pessoas com Deficiência, assinada em Nova York, em 30 de março de 2007. Esta convenção teve como produto no Brasil o Decreto no 6.949, de 25 de agosto de 2009. Após esta convenção, a capacidade civil passa a ser um direito fundamental da pessoa com 
deficiência. O Estatuto da pessoa com deficiência é resultado de um processo histórico de leis específicas que já vinham surgindo, mas que não foram utilizadas para criação de todo um arcabouço. 0 estatuto é um conjunto de leis que visa a inclusão através de medidas de caráter social da pessoa com deficiência.

A Lei Brasileira de Inclusão da Pessoa com Deficiência (Lei no 13.146/2015) é destinada a assegurar e promover, em condições de igualdade, o exercício dos direitos e das liberdades fundamentais da pessoa com deficiência. Esta lei foi motivada principalmente pelo anseio de se promover igualdade entre os indivíduos, pois, com sua entrada em vigor, tende a garantir o exercício dos direitos e das liberdades fundamentais, proporcionando a inclusão da pessoa com deficiência no meio social. O objetivo da lei seria o de derrubar as barreiras que impedem estas pessoas de participarem ativamente das tomadas de decisões.

Antes da criação desta lei as pessoas com deficiência, na maioria dos casos, não podiam tomar decisões por si mesmas, ficando privadas de certos atos da vida civil. Desta forma não se inseriam totalmente na sociedade, ficando cada vez mais excluídas, o que de certa forma faz com que aumente o preconceito e que dificulta cada vez mais sua convivência social.

Com a vigência da lei, as pessoas com algum tipo de limitação passaram a responder por si mesmas, não ficando mais impedidas, desde que suas condições permitam realizar qualquer ato da vida civil, podendo inclusive entrar no mercado de trabalho. Em certo sentido, a inclusão da pessoa com deficiência no meio social proporciona maior igualdade entre os indivíduos, essa inclusão é a maior motivação para criação dessa lei, pois ninguém deve ser excluído do meio social por possuir qualquer tipo de deficiência. A lei trouxe inúmeras alterações ao Código Civil Brasileiro. Sobre isto é que versará o próximo tópico.

\section{ALTERAÇÕES NO CÓDIGO CIVIL APÓS A LEI DE INCLUSÃO DA PESSOA COM DEFICIÊNCIA}

A publicação da Lei $n^{\circ}$ 13.146, de 2015, com vacatio legis - o intervalo entre a data de publicação de uma lei e sua entrada em vigor - de 180 dias, trouxe diversas garantias para as pessoas com deficiência. As mudanças provocadas pela lei interessavam diretamente a diversas áreas do direito, em especial ao Direito Civil. Pode-se dizer que a principal mudança do trazida pelo estatuto foi a exclusão da pessoa deficiente, seja qual for o tipo de deficiência como incapaz, tornando-a completamente capaz para exercer seus direitos, mudança essa de grande importância na busca pela igualdade.

Vale ressaltar que após a publicação da lei as pessoas com deficiência não podem mais ser tratadas com incapazes. No entanto isso não significa que, por exemplo, a pessoa com transtorno mental, em algum momento, não tenha a sua capacidade limitada, podendo vir em certas situações de transtorno ficar sujeita à curatela ${ }^{3}$. Foram revogados inúmeros artigos e incisos do Código Civil Brasileiro que tinham como temática as pessoas que tivessem algum tipo de deficiência entre estes os incisos I, II e III do Art. 3‥

O Art. 3ㅜ, do Código Civil de 2002, legislava sobre aqueles que possuíam algum tipo de deficiência que não tinham discernimento necessário para a prática de certos atos ou que por causa transitória não pudessem exprimir sua vontade seriam considerados incapazes. Com a revogação do artigo apenas crianças e adolescentes até 16 anos são considerado incapazes e o inciso III passou a compor o Art. 4 ainda do atual Código Civil brasileiro, o qual trata dos relativamente incapazes, sendo revogados os incisos II e III no que diz respeito aos que têm o discernimento reduzido por deficiência mental e os que não possuem desenvolvimento mental completo.

\footnotetext{
${ }^{3}$ Curatela é quando é dado a outrem, mediante processo legal, encargo a alguém capaz, para reger a pessoa e administrar seus bens daquele não poder fazer por si mesmo.
} 
Não podiam ser admitidos como testemunhas aqueles que por enfermidade ou deficiência intelectual não tivessem discernimento para a prática de certos atos da vida civil e com deficiência visual e auditiva, quando a ciência do fato que se quer provar dependia dos sentidos que lhes faltam como constava no Inciso II e III, do Art. 228 também do Código Civil brasileiro de 2002, sendo incluído pela lei 13.146 , o $\S 2^{\circ}$, podendo agora testemunhar em igualdade de condições como as demais pessoas, sendo-lhes assegurados todos os recursos de tecnologia assistiva. ${ }^{4}$

Não é mais nulo o casamento contraído pela pessoa com enfermidades mentais sem o discernimento para os atos da vida civil, que era tratado pelo inciso I, do Art. 1.548 do CC/2002. Antes podia ser revogada a autorização pelos pais, tutores ou curadores. Isso era considerado como erro essencial sobre a pessoa do cônjuge a falta de conhecimento, anterior ao casamento, de defeito físico irremediável e por falta de conhecimento de doença mental grave, que torne insuportável a vida em comum ao cônjuge enganado, com a nova redação não se considera isso um erro essencial, considera em relação a esse assunto apenas a ignorância anterior ao casamento de defeito físico que não caracterize deficiência.

Permanecem ainda sujeitos a curatela, os que por causa transitória ou permanente não puder exprimir sua vontade, os ébrios habituais viciados em tóxicos e os pródigos Art. 1.767, incisos, I, III e V do Código Civil de 2002.

É importante atentar-se para o fato de que no caso de curatela da pessoa com deficiência deverá ser assegurada a maior participação possível da pessoa curatelada, para obtenção do seu consentimento, pois é necessária a sua permissão. Em casos especiais poderá ser suprido o seu consentimento na forma de lei, Parágrafo Único, Art. 11, Lei no 13.146/2015. Poderá, apenas em caso de deficiência mental ou intelectual, ser promovido o processo pelo Ministério Público, não mais podendo, mesmo os pais, tutores ou cônjuge, ser deixado de lado. Ele deve ser promovido pela própria pessoa.
A pessoa com deficiência poderá escolher pelo menos duas pessoas idôneas para apoiar em suas decisões sobre atos da vida civil, pessoas de sua confiança com as quais mantenham vínculos, conforme entendimento do Art. 1.783-A, caput do Código Civil de 2002. Para formular o pedido a pessoa com deficiência e os apoiadores deverão prestar termos que contêm os limites do apoio a ser prestado e os compromissos dos apoiadores, contendo prazo de vigência do acordo e o respeito à vontade, aos direitos e aos interesses da pessoa que devem apoiar o pedido de decisão apoiada só será pedido pela pessoa a ser apoiada.

A decisão apoiada tem como objetivo guardar o direito de a pessoa com deficiência tomar suas próprias decisões no ordenamento civil sem precisar que outras pessoas tomem as decisões por ela. A pessoa apoiada ou qualquer pessoa poderá apresentar denúncia ao Ministério Público quando o apoiador agir com negligência, exercer pressão indevida ou não adimplir as obrigações assumidas, protegendo assim sua autonomia não deixando que terceiros decida por eles. A decisão apoiada não tem caráter permanente podendo a qualquer tempo a pessoa apoiada ou o apoiador solicitar o término de acordo firmado em processo de tomada de decisão apoiada, Art. 1.783-A, § 9o, do Código Civil de 2002.

\section{MUDANÇAS NO ÂMBITO PRÁTICO CAUSADA PELO ESTATUTO DA PES- SOA COM DEFICIÊNCIA}

As mudanças e as alterações após o Estatuto da pessoa com deficiência não se limitam apenas ao campo das normas. As alterações feitas no Estatuto acarretam diversas mudanças que devem ser realizadas no âmbito prático, desde o campo da educação até mudanças nas estruturas físicas no cotidiano para que possam facilitar a locomoção e a vida das pessoas com algum tipo de defici-

\footnotetext{
${ }^{4}$ Tecnologia Assistiva é um termo ainda novo, utilizado para identificar todo o arsenal de Recursos e Serviços que contribuem para proporcionar ou ampliar habilidades funcionais de pessoas com deficiência e consequentemente promover Vida Independente e Inclusão.
} 
ência. É inevitável que algumas levem mais tempo para estarem completas, pois demandam tempo e dinheiro. As mudanças devem acontecer sem obstáculos para que possam auxiliar aqueles que possuem direitos, de modo a facilitar a sua independência no dia a dia, diminuindo cada vez mais as dificuldades que ainda existem principalmente para a locomoção dessas pessoas.

Com as mudanças acarretas no Código Civil Brasileiro de 2002, pelo Estatuto da Pessoa com Deficiência no âmbito civil, acarretará mudanças também no âmbito pratico, pois melhorias deverão ser feitas para que as instituições, públicas ou privadas, atendam as necessidades das pessoas com deficiências. Tais melhorias colaborarão para que não fiquem tão dependentes de terceiros no seu dia a dia. Além das mudanças que dão maior autonomia para decidir sobre atos de sua vida civil, há também mudanças como, por exemplo, no transporte público no qual deverão se adaptar para transportar pessoas com deficiência de qualquer tipo.

Outra mudança acarretada pelo Estatuto da Pessoa com Deficiência que repercute no meio prático é em relação à educação formal, Art. 27. As instituições privadas não podem cobrar valores adicionais de qualquer natureza em suas mensalidades, anuidades ou matrículas das pessoas com deficiência. Também cabe ao poder público assegurar, criar, desenvolver, implementar, incentivar, acompanhar e avaliar o sistema educacional em todos os níveis e modalidades, Art. 28 caput, Lei 13.146. Além disso, cabe a ele buscar o aprimoramento dos sistemas educacionais, com a oferta da educação em Libras, planejar estudos de caso, participação dos estudantes e seus familiares nas diversas instâncias da comunidade escolar consoante o Art. 28, incisos, I à VIII, Lei 13.146. A pessoa com deficiência tem garantido também o acesso à educação superior e à educação profissional, a adoção de práticas pedagógicas inclusivas pelos programas de formação inicial e continuada pelos professores, oferta de profissionais de apoio escolar, conforme Art. 28, incisos IX à XIV, Lei 13.146.

Todos estes dispositivos citados no parágrafo anterior promoverão uma mudança no setor educacional fazendo com que os profissionais se especializem e obtenham apoio do governo no sentido de proporcionar uma melhora e para que as crianças que tenham deficiências não apresentem precariedades na educação, tendo as mesmas chances de aprender como as demais crianças "sem deficiência".

A atenção à educação para pessoas com deficiência tratada pela lei 13.146/15 como, por exemplo, o Art. 27, o qual constitui a educação como direito da pessoa com deficiência, devendo assegurar todos os níveis de aprendizado ao longo da vida, para que possa alcançar o máximo de desenvolvimento de seus talentos e habilidades físicas, sensoriais, intelectuais e sociais, segundo suas características, interesse e necessidades de aprendizagem, é sem dúvida uma das mais importante das mudanças provocadas pela Estatuto da Pessoa com Deficiência, pois garantir a pessoa com deficiência o ensino de qualidade é aproximar a pessoa com deficiência que ficava isolada das demais gerando um ganho social não somente para a pessoa com deficiência, mas também para toda a sociedade que irá compartilhar das suas dificuldades e barreiras, ajudando assim no processo de inclusão daquele indivíduo, que é o objetivo maior do Estatuto.

\section{CONSIDERAÇÕES FINAIS}

O objetivo do legislador, ao criar o Estatuto da Pessoa com Deficiência, consiste em diminuir as barreiras para as pessoas que possuem algum tipo de deficiência com vistas a torná-las mais independentes. Esta independência veio por meio da Lei 13.146 modificando os Art. $3^{\circ}$ e $4^{\circ}$ do Código Civil que tratava respectivamente as pessoas com deficiência como absolutamente ou relativamente in capazes no mundo civil. Em certo sentido o legislador quer mostrar que o ser humano não pode ser reduzido simplesmente a uma doença ou a uma deficiência. Antes a pessoa com deficiência era totalmente neutra no mundo jurídico ao ser interditada, ou seja, era nada mais que uma "morte" para o mundo jurídico. 
As mudanças ocorridas pela nova legislação vieram com atraso, pois, desde 2009, já deveriam ter sido implementadas, no sentido de trazer mais independência à pessoa com deficiência, por meio do Decreto no 6.949, de 25 de agosto de 2009. Entretanto o legislador só se preocupou em legislar sobre o assunto após a Lei 13.146 de 2015.

Todas as alterações feitas no Código Civil Brasileiro citadas no corpo do artigo por consequência do Estatuto da Pessoa com Deficiência são importantes para assegurar a autonomia necessária à pessoa com deficiência. Elas permitem que ela por si mesma possa decidir sobre assuntos de seu interesse sem necessitar da interferência de terceiros. No entanto em casos extremos a pessoa deficiente ainda poderá ser curatelada sendo essa curatela solicitada apenas pela própria pessoa ou em alguns casos pelo Ministério Público. Esta solicitação, porém, pode limitar a sua vontade como era feita anteriormente ao Estatuto. Apenas em poucos casos poderá ela ser curatelada, pois a curatela será limitada pelo juiz e podendo ela, a qualquer momento, solicitar o fim da curatela.

No que diz respeito às mudanças práticas acarretadas pelo Estatuto da pessoa com deficiência, pode-se dizer que a intenção é tornar mais fácil o dia a dia dessas pessoas que necessitam de amparo especial, fazendo com que possam, principalmente, se locomover de forma independente, visto que, de nada adiantaria garantir seus direitos se a pessoa não tiver os meios necessários para poder exercê-los.

Toda mudança em ensino, infraestrutura em locais públicos e privados ou em meios de transporte, poderá gerar um transtorno para toda a sociedade e para aqueles que deverão fazer esta mudança acontecer. Porém é totalmente necessário garantir a efetividade normativa (mudança da legislação) imposta pelo Estatuto, pois facilitará a vida das pessoas com deficiência e para a própria sociedade e as famílias, dando maior liberdade a elas para viver de forma independente e possibilitar a tão almejada inclusão social, já que por anos foram colocadas no limbo da lei ou foram tratadas como incapazes.

\section{REFERÊNCIAS}

ARAUJO, Luiz Alberto David; FILHO, Waldir Macieira da Costa. O estatuto da pessoa com deficiência epcd (lei 13.146, de 06.07.2015): algumas novidades. Revistas dos tribunais. São Paulo, vol. 962, p. 65-80, dez. 2015.

BRASIL. Constituição da República Federativa do Brasil. Brasília: Senado Federal, Subsecretaria de Edições Técnicas, 2002.

Decreto no 6.949, de 25 de agosto de 2009. Promulga a Convenção Internacional sobre os Direitos das Pessoas com Deficiência e seu Protocolo Facultativo, assinados em Nova York, em 30 de março de 2007. Brasília: Diário Oficial da União, 2009.

. Lei no 7.853, de 24 de outubro de 1989: Dispõe sobre o apoio às pessoas portadoras de deficiência, sua integração social, sobre a Coordenadoria Nacional para Integração da Pessoa Portadora de Deficiência - Corde, institui a tutela jurisdicional de interesses coletivos ou difusos dessas pessoas, disciplina a atuação do Ministério Público, define crimes, e dá outras providências. Brasília: Diário Oficial da União, 1989.

. Lei no 8.213, de 24 de julho de 1991: Dispõe sobre os Planos de Benefícios da Previdência Social e dá outras providências. Brasília: Diário Oficial da União, 1991.

Lei no 10.406, de 10 de janeiro de 2002 (com as alterações dadas pela Lei no 13.146, de 06 de julho de 2015): Código Civil Brasileiro. Brasília: Diário Oficial da União, 2002.

Lei no 13.146, de 06 de julho de 2015: Estatuto da Pessoa com Deficiência. Brasília: Diário Oficial da União, 2015.

COMPARATO, Fábio Konder. A afirmação histórica dos direitos humanos, 3. ed.-São Paulo: Saraiva, 2003

DINIZ, Maria Helena. Curso de direito civil brasileiro, vol 1. 29. ed. São Paulo: Saraiva, 2012.

DLUGOSZ, Vanessa Pereira. O impacto juridico e 
social na vida da pessoa com deficiência adquirida. Anais do EVINCI - UniBrasil. [S.I.], v. 1, n.4, p.11011117, 2015. Disponível em: <http://portaldepe riodicos.unibrasil.com.br/index.php/anaisevinci/ar ticle/view/935/911>. Acesso em 02 mai. 2017.

GALINDO, Bruno. A inclusão veio para ficar: o direito antidiscriminatório pós-adi 5357 e a educação inclusiva como direito da pessoa com deficiência. Direito e Desenvolvimento, [S.I.], v.7, n.1, p.4358, jun. 2017. Disponível em: <https://periodi cos.unipe.br/index.php/direitoedesenvolvimento/ article/view/300>. Acesso em: 28 mai. 2017.

KANT, Immanuel. Fundamentação da Metafísica dos Costumes. Tradução de Paulo Quintela - Lisboa: Edições 70, 2007.

MACCALI, Nicole et al. As práticas de recursos humanos para a gestão da diversidade: a inclusão de deficientes intelectuais em uma federação pública do Brasil. Revista de Administração Mackenzie. São Paulo, vol.16, n. 2, p. 157-187, apr. 2015. Disponível em: <http://www.scielo.br/scielo.php?script= sci_arttext\&pid=S1678-69712015000200157> Acesso em: 10 jun. 2017.

MARQUES, Heitor Romero et al. Metodologia da pesquisa do trabalho científico. 4.ed. Campo Grande: UCDB, 2014

MARTINS, Silvia Portes Rocha. O estatuto da pessoa com deficiência e as alterações jurídicas relevantes no âmbito da capacidade civil. Revistas dos tribunais. [S.I.], v. 974, p. 225-243, dez. 2016. Disponível em: <http://www.civel.mppr.mp.br/arqui vos/File/Artigo_Silvia_Portes_Rocha_Martins.pdf>.
Acessado em: 10 jun. 2017.

MIANES, Felipe Leão. Audiodescrição e processos de identificação através da cultura. Revista Textura - ULBRA. [S.I.], v. 18, n. 38, dez.2016. Disponível em: <http://www.periodicos.ulbra.br/index.php/ txra/article/view/2204/1951>. Acesso em 06 jun. 2017.

NADER, Paulo. Introdução ao Estudo do Direito. 36.ed. revisada e atualizada. Rio de Janeiro: Forense, 2014.

REQUIÃO, Marcelo. Estatuto da pessoa com deficiência altera regime civil das incapacidades. Revista eletrônica Consultor Jurídico. São Paulo, 2015. Disponível em: <http://www.conjur.com.br/2015-jul20/estatuto-pessoa-deficiencia-altera-regimeincapacidades>. Acessado em: 06 jun. 2017.

ROLIM, Luiz Antonio. Instituições de direito romano. 2. ed. rev. São Paulo: Revista dos Tribunais, 2003.

SARLET, Ingo; MARINONI, Luiz Guilherme; MITIDIERO, Daniel. Curso de Direito Constitucional. 4. ed. ampl. São Paulo: Saraiva, 2015.

TARTUCE, Flávio. Manual de direito civil, volume único. São Paulo: Método, 2011.

XAVIER, Avanci Duda. Inclusão da Pessoa com Deficiência: a grande barreira são as atitudes. // Congresso internacional de educação inclusiva. Campina Grande, 2016. Disponível em: < https:// editorarealize.com.br/revistas/cintedi/trabalhos/ TRABALHO_EV060_MD1_SA10_ID571_01092016 205234.pdf>. Acessado em: 01 jun 2017. 